\title{
The Correlation Between Social Systems and Epidemic Control in Modern China
}

\author{
Jiayi Chen ${ }^{1, a}$ \\ ${ }^{1}$ Shanghai Southwest Weiyu Middle School, Shanghai 200233, China \\ aEmail: chen39281746@163.com
}

\begin{abstract}
This article tries to explore the correlation between social systems and epidemic prevention and control, taking Shanghai and Nanjing in the Republic of China period as example. On the one hand, the epidemic outbreak and the need of its prevention and control is the drive to changes and improvements of the medical and social systems; on the other hand, an effective social system actively contributes to the prevention and control of the epidemic, while an ineffective social system will only make epidemic control difficult.
\end{abstract}

Keywords: Republic of China, Shanghai, Nanjing, epidemic prevention and control, social system

\section{INTRODUCTION}

From late Qing Dynasty to the Republic of China, China underwent tremendous social transformations, from a feudal empire to a semi-feudal and semi-colonial state, and then the new emerging capitalism during the period of Beiyang Warlords and the KuomintangCommunist War. The longtime of warfare made China continuously suffer the epidemic outbreaks. Since the 19th century, various types of epidemic viruses, such as cholera, typhoid fever, plague, smallpox and so on, began to spread into China in cities including Shanghai and Nanjing along the China ocean coast or the Yangtze River. During the period of Republic of China, epidemic outbreaks, small or large, kept going on year after year, because under the war existing though imperfect sanitary facilities were ruined, let alone building an integral epidemic control system. The epidemic got even worse because of the damaged health facilities as well as chaos during Japanese occupation in the Anti-Japanese War time. Improvements only came about after the People's Republic China was founded.

In fighting various epidemics from the end of Qing Dynasty to the Republic of China, the local governments and the people in Shanghai gradually established a social system to prevent and control the epidemics. The epidemics were enemies of the entire human society. People organized the anti-epidemic efforts under one or multiple social systems. However, the losses from the raging epidemics could also drive social system changes such as the port quarantine system and the periodic reporting of medical institutions. Therefore, the systems were being set up for epidemic control, the epidemics also helped to determine which system was more effective and shall be retained and be improved. This correlation between the social system and epidemic control became quite obvious in the period of the Republic of China, and provided a valuable example for future studies about epidemic prevention and medical systems of modern China.

However, a negative example occurred in Nanjing after the city suffered the massacre by the Japanese Army. The Japanese and their puppet government used the epidemic control measures to manipulate the Chinese people and society. Despite of the exceptional circumstances, any political forces or governments should confront themselves with the epidemic and make investments to set up appropriate social systems, as the criticality of epidemic control is universal irrespective of the ruling powers.

With a focus on Shanghai and Nanjing in the Republic of China period, this article tries to deep into Shanghai's responses to cholera and other epidemic outbreak and the setting up of social systems, as well as analyses the political and social system changes during the development of the epidemic after the fall of Nanjing city during the Anti-Japanese War, meanwhile it explores the correlation between the social system and epidemic control. 


\section{EPIDEMIC CONTROL IN MODERN SHANGHAI}

It is recorded in the History of Epidemic Prevention in Shanghai that cholera, typhoid, plague, and smallpox began to spread in Shanghai in the early 19th century. This was the time when the western countries set their foot on Shanghai one after another, accompanied by the epidemic viruses. Cholera virus that landed China in Qing Dynasty was one of them. Some government agencies began to realize the health problems and embark on making improvements, for example, in 1863, the Ministry of Public Concession set up a unit dedicated to road sanitation and garbage disposal. [1] In addition, the concession area also began to establish port quarantine system and build waterworks, which was considered the start of health and epidemic control in modern Shanghai.

The epidemic disease was rampant in Shanghai from late Qing Dynasty to early of Republic of China. The annual death toll went up and down, but the overall trend was upward. Cholera, for example, continued to spread in 1903, 1907, 1912, 1914 and 1919, separately with 162 , 655, 1307, 350 and 648 deaths. [1] Apparently, the death toll rose in general, and then began to decline after the establishment of the Republic of China. One of the reasons was that the newly established government of the Republic of China took thee setting up of health system rather seriously, and introduced western medical technology into China.

However, with the outbreak of wars one after another, epidemics also occurred frequently. From early 20th century till the middle of the Republic of China, the spread of cholera, smallpox and other diseases hit the peak. The worst time of all was in 1938, when 5407 Chinese died of cholera in August alone. During the Songhu Anti-Japanese War in 1938, the highest infection and death rate of smallpox in recorded years, at $0.1168 \%$ and $0.0382 \%$ respectively. [1]

As a result of the long-lasting wars, Shanghai, an ocean port city, became a breeding ground for cholera development. From the early Republic of China to the 1940s, cholera occurred frequently. Cholera in Shanghai was initially imported from overseas, but from 1930s it had gradually become an endemic disease in Shanghai.[2] After the victory of the Anti- Japanese War, the health facilities and environment were somewhat restored, but serious sanitation problems remained given limited manpower and supplies.

Even in wartime conditions, the government and social groups gradually established relevant laws, facilities, departments, publicity and so on, to cope with the epidemic. For example, the Shanghai Insurance Regulatory Commission was established in 1939 to provide disease prevention guidance, and free medical checks and treatment services to its members [3]. Despite of its limited impact, it also contributed to the epidemic control. In the 1946 cholera outbreak, Shanghai local government fought against this newly formed seasonal epidemic together with social organizations and the public. According to the statistics of Shanghai Health Records, a total of 4415 cases occurred and 353 people died. Compared with the cholera outbreak in the 1930s, this time Shanghai made great progress in its antiepidemic efforts.

\section{THE SOCIAL SYSTEM'S FUNCTION IN EPIDEMIC CONTROL}

The critical thing in anti-epidemics was not simply medical technology, manpower and supplies, a wellfunctioning social system was also extremely important, which orchestrates the task comprised of all elements like disinfection, hospitalization, manufacturing as well as distribution of medical supplies. The medical element and each person like individual soldiers, while the social system that integrates all of them like a general.

The Shanghai municipal government began to embark on sanitation and anti-epidemic efforts by setting up medical institutions and appropriate social systems since 1920s. The systems initially set up were about vaccination and traffic quarantine. In 1926 in the Chinese controlled district, the Shanghai government set up a medical institution known as the Songhu Commercial District Health Bureau, which later became the Shanghai Health Bureau. In 1936, Shanghai Health Bureau, joined by other relevant agencies, public groups and individuals, as well as medical experts, established the Shanghai Epidemic Prevention Committee, which later became a permanent organization. On May 1, 1946, the Shanghai Epidemic Prevention Committee and the Shanghai Health Bureau announced free cholera vaccination for the Shanghai people.

When the vaccination just began, many Shanghainese were skeptical, and many poor people even more so, as the vaccination was beyond their education and medical knowledge. During a cholera outbreak afterwards, continuous vaccination was enforced, which produced remarkable results. Further an airport quarantine system was implemented. It's a long-term process to enhance medical knowledge and to change mindset of the people. Besides the usual disinfection, vaccination and medical treatment, the health institutions had a greater responsibility to guide and prepare the people on how to respond to epidemics. When each individual person was well-prepared, the entire society can respond quickly in full force to an epidemic outbreak. And when everyone can look after themselves and moreover support the society in the anti-epidemic efforts, the government could direct its time and resources to medical research and breakthrough, which eventually will bring about enhancements at all levels of the anti-epidemic work. 
The second implementation was regarding water supply and food safety. Since 1933 a water quality inspection report system had been implemented in Shanghai. The water was inspected daily, and test results published in weekly newspapers. However, most people and the poor ones still used water from the river and well. Tap water supply was enabled later by establishing retail agents. In terms of food safety, the Shanghai Health Bureau and the police station strictly controlled food and drink products, checked and banned illegal products at any time.

The other measure was the sanitation and garbage disposal. Before implementation, the street cleaners were poorly paid hence streets filled with garbage, health funds were insufficient hence the employees de-motivated. The government organized clean-up activities with assistances of US military truck, and made the people clean up inside and outside of their households, which significantly improved sanitary conditions. Other measures implemented concurrently include mosquito/fly/flee/rate control, sanitation promotion, and cholera vaccination, etc.

Therefore, during cholera outbreak in Shanghai in 1946, the Shanghai municipal government took corresponding measures and assumed a lead role in the anti-cholera efforts. During the 1946 cholera outbreak, most of the infected people were factory workers and poor people, who lived in slum areas and had no access to tap water. The Health Bureau assigned 10 mobile medical teams to "implement door-to-door vaccination in the worst cholera-stricken Huxi District". This targeted forced vaccination well curbed the spread of the epidemic, despite of the resistance and misperception by some. Nonetheless, the forced vaccination reflected negligence in public health training by the government in previous years, probably due to the war. The outbreak reached its peak in July 1946 when the epidemic prevention committee cautioned the public to watch out as hospitals were all full, and construction was underway of all mobile wood houses donated by the Shanghai Branch of the General Administration of the Republic of China. In August 1946, the epidemic situation began to decline, and the epidemic prevention forces concentrated in Zhabei, spraying DDT on the earth well for disinfection. In September 1946, the cholera outbreak basically ended.

Throughout the 1930s and 1940s, the cholera outbreak in 1946 was the biggest hit, but the number of deaths and infection was not the highest, which may be attributed to the improved anti-epidemic measures, as well as changed administration. Shanghai had been dominated by multiple parties with their respective systems, hence making a unified health administration impossible. By 1946 China won the war against the Japanese and recovered the lost land and administration power. Meanwhile the application of western medical technology significantly enhanced disinfection and treatment.

In a nutshell, epidemic control does not begin only after outbreak. It goes hand in hand with the establishment of a regular epidemic prevention system and corresponding social, medical and health systems, before any epidemic outbreak. During the period of the Republic of China, the Shanghai Municipal Government of the Republic of China helped to improve daily health system, which contributed to epidemic control to a certain extent.

\section{THE IMPACT OF THE EPIDEMIC}

The epidemic produces multifaceted impact on the people and society. First and foremost, epidemic killed people and cost people their wealth and properties. Law and regulatory changes or additions became necessary to prevent the huge harm done to the society by the epidemic. The epidemic typically spread where there were people movements and circulation of products. Epidemic control shall require cutting down of such activities, which slowed down the economy. But the medical system required sufficient funds, hence the government had to make careful decisions in allocating funds. Both economy and medical system were closely related to people's lives. During an economy slowdown or recession, in order to make a living, people maybe be forced to do things that violate the anti-epidemic rules and regulations, and therefore made the epidemic control even more difficult. Some people who held conventional views opposed vaccination would give up holding up to the conventional knowledge and started to embrace new medical development, after they learned about the benefit of vaccination, and then subsequently changed the local customs and culture.

Before the fall of Nanjing, the national government health department, Nanjing health office and all other health and epidemic prevention institutions got evacuated, and a large number of public and private hospitals were either evacuated or closed down, the rather complete public health system before the war now went down completely. Gulou Hospital, the Affiliated Hospital of Jinling University, was the only medical institution that could provide medical treatment for the people after the fall of Nanjing. [4]

Since lacking of hospital and medical treatment, general sanitary conditions were extremely poor in the post-massacre Nanjing. All over the place were buildings and constructions ruined by the Japanese military, as well as dead bodies and human waste. The refugees were in poor health condition, as they suffered long time of war, and lack of clean food or starvation, after fleeing from home. Epidemic diseases spread and took away many lives like war. And post-massacre the medical supply was very limited. 
Nanjing then was ruled by the Japanese military and a puppet government, whose primary goal was to strengthen their ruling position and power in Nanjing. The epidemic outbreak was seized by them as an opportunity to carry out the so-called pacification policy ( Xuan $\mathrm{Fu}$ ), namely propaganda and comfort, the purpose of which was to "make it clear to the Chinese in the war area that the Great Japanese Empire intends to eliminate anti-Japanese and pro-Europe \& USA ideas from the Chinese, and that it is Japan that they should depend on, it is Japan that can guarantee them live and work in peace." [4] Therefore, neither did the Japanese respond to the epidemic from a humanitarian and lifesaving standpoint, nor did them make any material investments to improve the local medical and health condition, hence hardly any achievement was accomplished in the epidemic control front at the very beginning.

In contrast, some international organizations and Gulou Hospital did not give up their efforts even under the difficult circumstances and contributed significantly to epidemic control.

Amidst the raging epidemic, the huge difference between Japanese and international efforts brought pressure to the Japanese side. They worried that the Nanjing people under their rule would resist the Japanese rule, so they changed their previous policy. " Japanese diplomats repeatedly called on Japanese largest medical organization in China, Tongren Association, to participate as soon as possible Nanjing Medical "Xuanfu" affairs." On March 16, 1938, the Japanese Consul General in Nanjing Yoshikazu Hanawa once again proposed that prevention and control of infectious diseases was imminent. Local international relief committees and American hospitals were actively engaged in activities, which would encourage the Chinese people to rely on the Europe and American. To win over the people, they claimed to take appropriate measures to quickly deploy 500,000 person times of varicella, typhoid, and cholera vaccines to the local area, and send experts to set up medical institutions in municipal hospitals, so as to achieve 500 person times of treatment per day.

On May 3, 1938, after the Nanjing Hospital of the Greater Japan colleagues Association (hereinafter referred to as "Nanjing hospital") was opened at the former site of the municipal hospital, the diagnosis and treatment medial team "not only engaged in diagnosis and treatment for regular patients, but also assisted the epidemic prevention work of Nanjing from the first to the fifth districts. It also repeatedly assigned to the Xia Guan area medical staff to provide vaccination for the public"

The epidemic development defeated the Japanese original empty medical "Xuan Fu" policy, and thanks to the international influence, it forced the Japanese to change their position and engaged in some practical anti- epidemic efforts, which turned out to be effective, despite it was never their intention to free the Chinese from the suffering.

\section{CONCLUSION}

Since the Republic of China time, Shanghai has gone through many epidemic crises, big or small. When facing with the epidemics, both the Nanjing National Government and the Japanese puppet government had to deal with and solve many problems caused by the epidemic. It was in this process that the epidemic prevention system in Shanghai, Nanjing and other places was established and improved continuously in the period of the Republic of China.

A social system is the backbone and center core of the entire society. It must have a strong capability of taking appropriate actions, making effective changes and enhancements to cope with any epidemic crisis. It will have to carefully weigh and consider pros and cons, and decide whose interests it shall speak for between the powerful and the general public.

From the epidemic prevention experience of Shanghai in the Republic of China, social system and epidemic prevention and control are interrelated. Only by establishing a good and positive social system can we deal with the epidemic more efficiently.

\section{REFERENCES}

[1] Shanghai Tongzhi Museum, History of Shanghai Epidemic Prevention. Shanghai Science Popularization Press, June 1, 2003.

[2] Jia Qiao. Cholera in Shanghai, 1938 [D]. Fudan University, 2004

[3] Shanghai Health Care Association published "Education Monthly (Shanghai)" in 1939 [Volume 1, issue 1, page 84]

[4] Zhang Huiqing: "Xuanfu" or Control, Health Administration in Nanjing during the Post Holocaust Period. Nanjing Journal of Social Sciences, 2018(11). 